\title{
Atividade do óleo de Eucalyptus citriodora e Azadirachta indica no controle de Colletotrichum acutatum em morangueiro
}

\author{
Cláudia Regina Dias-Arieira ${ }^{*}$, Lucas da Rocha Ferreira ${ }^{1}$, Jailson de Oliveira Arieira² ${ }^{2}$ Edenilson Gonçalves Miguel ${ }^{1}$, \\ Mateus Augusto Donega ${ }^{3}$, Regina Cássia Ferreira Ribeiro ${ }^{4}$
}

${ }^{1}$ Universidade Estadual de Maringá, Campus Regional de Umuarama, Estrada da Paca s/n, Bairro São Cristóvão, CEP 87507-190, Umuarama, PR; ${ }^{2}$ Universidade Paranaense, Av. Londrina, Umuarama, PR; ${ }^{3}$ Universidade de São Paulo, ESALQ, Piracicaba, 13418-900; ${ }^{4}$ Universidade Estadual de Montes Claros, Campus de Janaúba, CP 91, 39440-000, Janaúba, MG.

Autor para correspondência: Cláudia Regina Dias-Arieira (cdiasarieira@brturbo.com.br)

Data de chegada: 23/04/2009. Aceito para publicação em: 15/07/2010.

\section{RESUMO}

Dias-Arieira, C.R.; Ferreira, L.R.; Arieira, J.O.; Miguel, E.G.; Donega, M.A.; Ribeiro, R.C.F. Atividade do óleo de Eucalyptus citriodora e Azadirachta indica no controle de Colletotrichum acutatum em morangueiro. Summa Phytopathologica, v.36, n.3, p.228-232, 2010.

A flor-preta é uma das doenças mais importantes do morangueiro e a busca por alternativas de controle tem sido uma constante, principalmente em áreas de cultivo orgânico. Assim, objetivou-se avaliar a eficiência, in vitro e in vivo, dos óleos de Eucalyptus citriodora e Azadirachta indica no controle de Colletotrichum acutatum em morangueiro. No experimento in vitro determinou-se a inibição do crescimento micelial quando o fungo foi submetido aos extratos nas concentrações de $0 ; 0,25 ; 0,5 ; 1,0$ e $1,5 \%$. No campo, avaliou-se o controle da doença com a aplicação dos óleos nas concentrações de $0,0,5$ e $1,0 \%$, pulverizados em intervalos de 7,15 e 30 dias, em plantas inoculadas com suspensão de $10^{6}$ conídios $/ \mathrm{mL}$. As avaliações foram realizadas semanalmente, observando-se a ocorrência e tamanho de lesões no pedúnculo e nos frutos, abortamento floral, produtividade, e ocorrência natural da doença. In vitro todos os tratamentos apresentaram redução significativa do crescimento micelial do fungo quando comparados ao controle. No campo, apenas o óleo de nim apresentou efeito significativo, reduzindo o abortamento floral e a ocorrência de frutos doentes advindos de flores inoculadas. Porém, maior ocorrência natural de doença foi observada quando a dosagem de $1,0 \%$ foi aplicada semanalmente.

Palavras-chave adicionais: flor-preta, morango, óleo essencial, nim, eucalipto.

\section{ABSTRACT}

Dias-Arieira, C.R.; Ferreira, L.R.; Arieira, J.O.; Miguel, E.G.; Donega, M.A.; Ribeiro, R.C.F. Eucalyptus citriodora and Azadirachta indica oil activity in the control of Colletotrichum acutatum, in strawberry crop. Summa Phytopathologica, v.36, n.2, p.228-232, 2010.

Anthracnose is one of the most important diseases in strawberry crop, and the search for control alternatives has been frequent, especially in organic cultivation areas. Thus, the present study aimed to evaluate the in vitro and in vivo efficiency of Eucaliptus citriodora and Azadirachta indica oil on the control of Colletotrichum acutatum in strawberry. In the in vitro experiment, mycelial growth inhibition was determined when the fungus was subjected to extracts at the following concentrations: 0; $0.25 ; 0.5 ; 1.0$; and $1.5 \%$. In the field, the disease control was evaluated through oil spraying at $0,0.5$ and $1.0 \%$ concentrations at intervals of seven, fifteen and thirty days, in plants inoculated with $10^{6}$ conidia $/ \mathrm{mL}$ suspension. Evaluations were weekly performed, and parameters such as occurrences and size of lesions in the peduncle and in the fruits, flower abortion, productivity, and natural disease occurrences were observed. In vitro, all treatments showed significant reduction in the mycelial growth relative to control. In the field, only neem oil had a significant effect decreasing flower abortion and the occurrences of sick fruits originated from inoculated flowers. However, natural disease occurrence was higher when $1.0 \%$ was weekly sprayed.

Keywords: anthracnose, strawberry, essential oil, neem, eucalyptus.

Atualmente, a flor preta é considerada uma das mais destrutivas doenças do morangueiro (Fragaria x ananassa Duch.). O agente causal da doença é o fungo Colletotrichum acutatum Simmonds que, além de infectar as flores, causa sintomas em frutos, pedúnculos, folhas, meristemas apicais e parte superior do rizoma (25). As perdas ocasionadas variam entre 30 e $68 \%$ (13). Contudo, a destruição total da lavoura pode ocorrer se as condições climáticas forem favoráveis ao fungo.

Os principais sintomas da doença são lesões escuras que se iniciam no cálice e, posteriormente, atingem o botão ou a flor, tornando-os secos, mumificados e de coloração castanho escura. O pistilo, ovário e cálice ficam totalmente secos e escuros. Nos folíolos observa-se a presença de manchas necróticas irregulares. O fungo é favorecido por temperaturas em torno de 25 a $30^{\circ} \mathrm{C}$ e alta umidade. Períodos de chuva por mais de dois dias consecutivos são altamente favoráveis ao rápido desenvolvimento da doença. Sob estas condições, observa-se a formação de massas rosadas de conídios do fungo sobre os órgãos afetados (25).

Em áreas novas o patógeno é introduzido principalmente por mudas contaminadas (24), e a sobrevivência ocorre nos restos culturais que servem como fonte de inóculo para os cultivos posteriores. A disseminação da doença nos canteiros dá-se pela água de chuva e 
irrigação, sendo favorecida pela cobertura plástica do canteiro. Adubações pesadas de nitrogênio e fósforo podem promover o aumento da incidência da doença (13).

No que tange ao controle, o emprego de cultivares resistentes ainda é limitado, visto que a maioria dos genótipos cultivados é suscetível. Além disto, não existem fungicidas que possam ser oficialmente recomendados para o controle da flor preta, sendo os produtos registrados para antracnose do morangueiro (Colletotrichum fragariae Brooks) de baixa eficiência para C. acutatum (24).

Além destes fatores, atualmente o mercado de produtos orgânicos encontra-se em expansão e a busca por métodos alternativos de controle de doenças tem sido uma constante. Neste contexto, diversas plantas medicinais vêm sendo avaliadas para o controle de fungos fitopatogênicos. Pesquisas têm indicado que extratos de plantas podem apresentar efeito direto sobre o fungo, alterando a germinação, formação de apressório, crescimento de hifas ou produção de esporos, ou ainda apresentar efeito sobre a planta, por indução de mecanismos de resistência $(4,10,16,17)$.

Diante do exposto, o trabalho objetivou avaliar a atividade dos óleos de eucalipto (Eucaliptus citriodora Hooker M.) e nim (Azadirachta indica Juss.) sobre o crescimento micelial de C. acutatum, in vitro, e no controle da doença no campo.

\section{MATERIAL E MÉTODOS}

\section{Teste in vitro}

Para a realização do experimento, preparou-se o BDA e adicionouse a ele óleo de nim ou óleo de eucalipto nas concentrações de $0,0,25$; 0,5; 1,0 e 1,5\% (v:v). Após autoclavagem, o material foi vertido em placas de Petri com nove centímetros de diâmetro. No centro de cada placa foi depositado um disco de micélio de $C$. acutatum com $0,8 \mathrm{~cm}$ de diâmetro. A população pura do fungo utilizada no experimento foi anteriormente isolada de morangueiro e gentilmente cedida pela Clínica de Fitopatologia da Universidade Estadual de Maringá-Campus Sede. A população foi previamente multiplicada em placas de Petri contendo BDA.

As placas contendo os tratamentos foram incubadas em B.O.D. a $27{ }^{\circ} \mathrm{C}$ e o crescimento micelial avaliado após dois, quatro e seis dias, usando-se régua milimetrada. $\mathrm{O}$ delineamento experimental foi inteiramente casualizado, com quatro repetições, sendo as médias comparadas pelo teste Tukey a $5 \%$ de probabilidade.

\section{Avaliação no campo}

O experimento foi conduzido na Universidade Estadual de Maringá - Campus Regional de Umuarama, entre os meses de abril e agosto de 2006. Mudas de morangueiro cultivar Dover foram transplantadas para vasos com capacidade para $2 \mathrm{~L}$, contendo solo esterilizado. Cada vaso recebeu duas mudas e foi mantido sobre bancadas em condição ambiente. As plantas foram adubadas semanalmente com $50 \mathrm{~mL}$ de solução de NPK (4-14-8) e irrigadas sempre que necessário.

Após 45 dias do transplantio, iniciou-se a pulverização das plantas com os produtos (óleo de nim ou óleo de eucalipto), nas concentrações 0, 0,5 e 1,0\%, diluídos em água. As aplicações foram realizadas periodicamente, com intervalos de sete, quinze ou trinta dias. Cada tratamento constou de quatro repetições.

Após 90 dias do transplantio, no início da fase de florescimento, realizou-se a inoculação das plantas. Para obtenção do inóculo, o fungo foi multiplicado em placas de Petri, contendo o meio BDA, por dez dias, sendo mantida a B.O.D. a $27^{\circ} \mathrm{C}$. Posteriormente, adicionou-se às placas $10 \mathrm{~mL}$ de água destilada esterilizada, e os conídios foram removidos com o auxílio de um pincel. A suspensão foi ajustada para $10^{6}$ conídios/mL, utilizando-se câmara de Neubauer e microscópio óptico.

A suspensão de conídios foi aplicada em diferentes partes da planta, pincelando-as com a suspensão do inóculo até o escorrimento. No pedúnculo foi feito um ferimento longitudinal com aproximadamente $1,5 \mathrm{~cm}$ de comprimento, usando agulha hipodérmica. Os botões florais e os frutos jovens foram feridos com quatro furos feitos com agulha hipodérmica. Em cada vaso, ou seja, para cada tratamento, foram inoculados três pedúnculos, três botões florais e três frutos jovens. Cada parte inoculada foi marcada amarrando-se a ela uma fita colorida.

As avaliações iniciaram-se sete dias após a inoculação e foram feitas semanalmente, avaliando-se: ocorrência de sintomas no pedúnculo e tamanho da lesão, abortamento floral, ocorrência de lesões nos frutos e tamanho das lesões e produtividade. Além da ocorrência de sintomas nas partes inoculadas, avaliou-se também a ocorrência natural de sintomas.

As médias das temperaturas máximas e mínimas registradas no período foram de $26,70{ }^{\circ} \mathrm{C}$ e $15,84{ }^{\circ} \mathrm{C}$, respectivamente.

$\mathrm{O}$ desenho experimental foi um fatorial $3 \times 4$, sendo três dosagens e quatro épocas de aplicação do produto. Os valores obtidos durante a avaliação foram submetidos à análise fatorial e teste de média ScottKnott a 5 e $10 \%$ de probabilidade, usando o programa estatístico SISVAR. Para as variáveis que apresentaram interação, realizou-se a análise de regressão pelo programa SPSS. Foram avaliados os modelos linear, quadrático, cúbico, exponencial e logarítmico.

\section{RESULTADOS E DISCUSSÃO}

\section{Teste in vitro}

Observou-se que o crescimento micelial do fungo foi significativamente inibido com a utilização dos óleos, independente da sua concentração. Contudo, foi possível observar (Tabela 1) que as concentrações de 1,0 e $1,5 \%$, tanto de óleo de eucalipto, quanto de nim, foram as que proporcionaram maiores reduções no desenvolvimento fúngico, não diferindo estatisticamente entre si. As concentrações de 0,25 e $0,5 \%$ apresentaram médias intermediárias quando comparadas aos outros tratamentos.

A atividade antifúngica de óleos essenciais sobre espécies de Colletotrichum já foi evidenciada por outros pesquisadores. Bernardo et al. (3) observaram $100 \%$ de inibição na germinação de conídios de C. graminicola (Ces.) Wils quando expostos ao óleo de Ocimum basilicum L., Baccharis trimera (Less.) DC. e Ruta graveolens L. Por

Tabela 1. Diâmetro médio da colônia e porcentagem de inibição do crescimento micelial de $C$. acutatum exposto a diferentes concentrações de óleo de nim (A. indica) e óleo de eucalipto (E. citriodora), após seis dias de incubação a $27^{\circ} \mathrm{C}$

\begin{tabular}{ccccc}
\hline Concentrações & $\begin{array}{c}\text { Óleo }^{1} \\
\text { de nim }^{1}\end{array}$ & $\begin{array}{c}\text { Porcentagem de } \\
\text { inibição }^{2}\end{array}$ & $\begin{array}{c}\text { Óleo de } \\
\text { eucalipto }^{1}\end{array}$ & $\begin{array}{c}\text { Porcentagem de } \\
\text { inibição }^{2}\end{array}$ \\
\hline 0,00 & $9,0 \mathrm{a}$ & - & $9,0 \mathrm{a}$ & - \\
0,25 & $2,3 \mathrm{~b}$ & 74,4 & $5,8 \mathrm{~b}$ & 35,6 \\
0,50 & $2,0 \mathrm{bc}$ & 77,8 & $4,3 \mathrm{~b}$ & 52,2 \\
1,00 & $1,4 \mathrm{c}$ & 84,4 & $0,8 \mathrm{c}$ & 91,1 \\
1,50 & $1,4 \mathrm{c}$ & 84,4 & $0,8 \mathrm{c}$ & 91,1 \\
\hline
\end{tabular}

Médias seguidas pela mesma letra na coluna não diferem entre si pelo teste Tukey 5\%. ${ }^{2}$ Valores comparados ao máximo crescimento micelial (controle). 
outro lado, Stangarlin et al. (23) constataram que o extrato bruto não autoclavado de E. citriodora, estimulou a germinação de esporos de $C$. graminicola, contudo houve redução de até $34 \%$ na formação de apressórios, quando submetidos a concentrações do extrato acima de $10 \%$.

Observou-se a inibição completa do crescimento micelial do fungo quando exposto ao óleo de eucalipto nas concentrações de 1,0 e 1,5\% (Tabela 1), uma vez que o diâmetro respectivo do crescimento equivale ao tamanho do disco de micélio depositado na placa. Bonaldo et al. (4) relataram que extratos aquosos autoclavado de E. citriodora, com concentrações superiores a 5\% inibiram a germinação de esporos de Colletotrichum lagenarium (Pass.) Ells \& Halst em mais de 90\%, verificando inclusive que, a autoclavagem do extrato promoveu maior inibição. Extratos e óleo de E. citriodora foram eficientes para controlar também o crescimento micelial de Didymella bryoniae (Fuckel) Rehm (10), Sclerotium cepivorum Berk (20) e Alternaria triticina Prasada e Prabhu (21).

Inibições superiores a $75 \%$ também foram obtidas quando o fungo foi exposto ao óleo de nim, nas concentrações acima de $0,5 \%$ (Tabela 1). No trabalho realizado por Ogbebor et al. (18), além do extrato de A. indica reduzir significativamente o crescimento micelial de C. gloeosporioides (Penzig) Saccardo, promoveu a redução de $34,62 \%$ na germinação de esporos, após cinco dias de incubação. Extratos metanólicos de nim promoveram inibições na ordem de 20,7 e 24,4\% do crescimento micelial de C. lindemuthianum (Sacc. $\&$ Magnus) Brioso e Cavara e C. dematium (Pers.:Fr) Grove, respectivamente (11).

Diversas substâncias com efeito antifúngico têm sido isoladas de E. citriodora e A. indica. No primeiro destacam-se principalmente o citronelol (aproximadamente 85\%), além de geraniol, isopulegol, cineol, estragol, $\alpha$ e $\beta$ pineno, $\beta$ cimeno, entre outras (8). Apesar de o citronelol ter sido citado como o principal responsável pelo controle da podridão provocada por Botrytis cinerea Pers. em maçãs, não foi eficiente em controlar C. gloeosporioides nestes frutos (14).

Em A. indica, a azadiractina e os terpenóides são as substâncias mais comumente citadas com esta atividade. Govindachari et al. (11) observaram que a azadiractina, quando usada pura, não apresentou atividade antifúngica expressiva, porém, seu efeito foi acentuado quando se adicionou terpenóides, indicando o efeito sinergístico destas substâncias.

\section{Avaliação no campo}

Nos experimentos realizados no campo, não houve interação significativa entre os fatores avaliados, épocas de aplicação e dosagens, quando se utilizou o extrato de eucalipto. Esses resultados são semelhantes aos observados por Ogbebor et al. (18), no qual plantas que foram eficientes em controlar o crescimento micelial de C. gloeosporioides, como Ageratum conyzoides L., Jatropha curcas L. e Vernonia amygdalina Del., apresentaram índice de doença superior à testemunha, quando aplicadas no campo.

No entanto, no trabalho realizado por Bonaldo et al. (4), o extrato aquoso autoclavado de E. citriodora induziu a síntese de fitoalexinas em cotilédones de soja quando aplicado numa concentração igual ou superior a $10 \%$; no caso de extrato não autoclavado, a indução ocorreu a partir da dosagem de $15 \%$. No mesmo experimento os autores observaram que a aplicação do extrato não autoclavado reduziu o tamanho das lesões provocadas por $C$. lagenarium em folhas de pepino, contudo não se observou efeito sistêmico na indução de resistência.

Outros trabalhos relatam a eficiência do extrato de E. citriodora no controle de fungos, mas a maioria deles avalia o crescimento micelial em condições controladas e, muitas vezes, a eficiência envolve dosagens elevadas do óleo. Stangarlin et al. (23) observaram que a redução de 14 a $34 \%$ na formação de apressórios de $C$. graminicola foi obtida quando o extrato de E. citriodora foi aplicado em concentrações superiores a $10 \%$. No trabalho realizado por Lee et al. (14), o óleo de E. citriodora inibiu o crescimento dos fungos B. cinerea, Rhizoctonia solani Kühn, Fusarium oxysporum Schlecht. e Pythim ultimum Throw. em 91, 87, 57 e 50\%, respectivamente, porém não inibiu o crescimento micelial de $C$. gloeosporioides.

Nos experimentos desenvolvidos por Diniz et al. (9), a maioria dos extratos de plantas avaliados foi pouco eficiente em reduzir a intensidade de requeima em tomateiro, e os autores consideram que quatro fatores devem ser considerados nestes casos: a ineficiência dos compostos presentes nos extratos, o baixo conteúdo de substâncias tóxicas ao fungo, as condições ambientais favoráveis à doença, e/ou variabilidade dos dados obtidos.

No que tange ao óleo de nim, a ocorrência natural de doença foi influenciada pela época de aplicação e dosagens (Tabelas 2 e 3). As dosagens de 0,5 e $1,0 \%$ estimularam a ocorrência natural de sintomas em frutos, quando comparadas ao controle, porém não diferiram estatisticamente entre si (Tabela 2). O estudo da interação indicou que a dosagem de $1,0 \%$ aplicada semanalmente foi a que possibilitou maior ocorrência natural da doença nos frutos (dados não apresentados), diferindo estatisticamente das demais interações $(\mathrm{P}<0,05)$.

Menor ocorrência de abortamento de flores de morangueiro inoculadas com $C$. acutatum foi observada quando se utilizou óleo de nim na dosagem de $0,5 \%$ (Tabela 2), independente da época de aplicação, ou seja, não foi constatada interação entre os fatores. Nos frutos que resultaram das flores inoculadas, as dosagens de 0,5 e $1,0 \%$ promoveram redução significativa $(\mathrm{P}<0,05)$ no surgimento de sintomas. Neste caso, a dosagem de $0,5 \%$ aplicada quinzenalmente apresentou maior redução no número de frutos lesionados, sendo a interação significativa a 5\% (Figura 1). A Figura 1 mostra que para aplicação mensal inverte-se a dosagem mais eficiente, aumentado o controle a $1,0 \%$, confirmando a interação entre os fatores.

Tabela 2. Ocorrência de sintomas e produtividade de morangueiro inoculado com C. acutatum, submetido a diferentes dosagens de óleo de nim.

\begin{tabular}{|c|c|c|c|c|c|c|c|}
\hline Dosagem & FI* & FFI* & $\mathbf{A F} * *$ & $\mathbf{P L} *$ & CLP* & $\mathbf{O N} *$ & Prod* \\
\hline Test & $1,50^{\mathrm{ns}}$ & $1,00 \mathrm{a}$ & $1,50 \mathrm{a}$ & $2,75^{\mathrm{ns}}$ & $11,72^{\mathrm{ns}}$ & $10,00 \mathrm{a}$ & $154,25^{\mathrm{ns}}$ \\
\hline $0,5 \%$ & 2,58 & $0,08 \mathrm{~b}$ & $0,25 \mathrm{~b}$ & 2,67 & 15,60 & $16,08 \mathrm{~b}$ & 153,17 \\
\hline $1,0 \%$ & 1,83 & $0,50 \mathrm{~b}$ & $1,25 \mathrm{a}$ & 2,42 & 9,75 & $18,87 \mathrm{~b}$ & 162,08 \\
\hline $\mathrm{CV}(\%)$ & 47,1 & 19,6 & 129,8 & 28,8 & 105,4 & 26,5 & 22,2 \\
\hline
\end{tabular}

FI: frutos inoculados; FFI: frutos originados de flores inoculadas; AF: abortamento floral; PL: pedúnculos lesionados; CLP: comprimento das lesões nos pedúnculos (cm); ON: ocorrência natural da doença; PROD: produtividade (g). Médias seguidas pela mesma letra nas colunas não diferem entre si pelo teste Scott-Knot a 5\% (*) e 10\% (**) de probabilidade. 
Tabela 3. Ocorrência de sintomas e produtividade de morangueiro inoculado com $C$. acutatum, submetido a diferentes épocas de aplicação do óleo de nim.

\begin{tabular}{llllllll}
\hline Época & FI $^{*}$ & FFI* & AF* & PL* & CLP* & ON* & PROD* \\
\hline Test & $1,50^{\text {ns }}$ & $1,00^{\text {ns }}$ & $1,50^{\text {ns }}$ & $2,75^{\text {ns }}$ & $11,72^{\text {ns }}$ & $10,00 \mathrm{a}$ & $154,25^{\text {ns }}$ \\
Seman & 2,62 & 0,38 & 0,88 & 2,50 & 10,15 & $16,62 \mathrm{~b}$ & 144,86 \\
Quinzen & 2,00 & 0,38 & 0,88 & 2,62 & 18,35 & $15,85 \mathrm{~b}$ & 174,25 \\
Mensal & 2,00 & 0,12 & 0,50 & 2,50 & 9,52 & $18,75 \mathrm{~b}$ & 153,75 \\
\hline CV $(\%)$ & 47,1 & 149,6 & 129,8 & 28,8 & 105,4 & 26,5 & 22,2
\end{tabular}

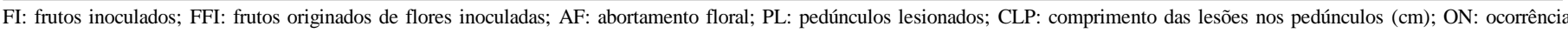
natural da doença; PROD: produtividade (g). Médias seguidas pela mesma letra nas colunas não diferem entre si pelo teste Scott-Knot a 5\% (*) e $10 \%$ (**) de probabilidade.

Figura 1. Interação entre época de aplicação e dosagens do óleo de nim sobre ocorrência de frutos sintomáticos originados de flores inoculadas com Colletotrichum acutatum.

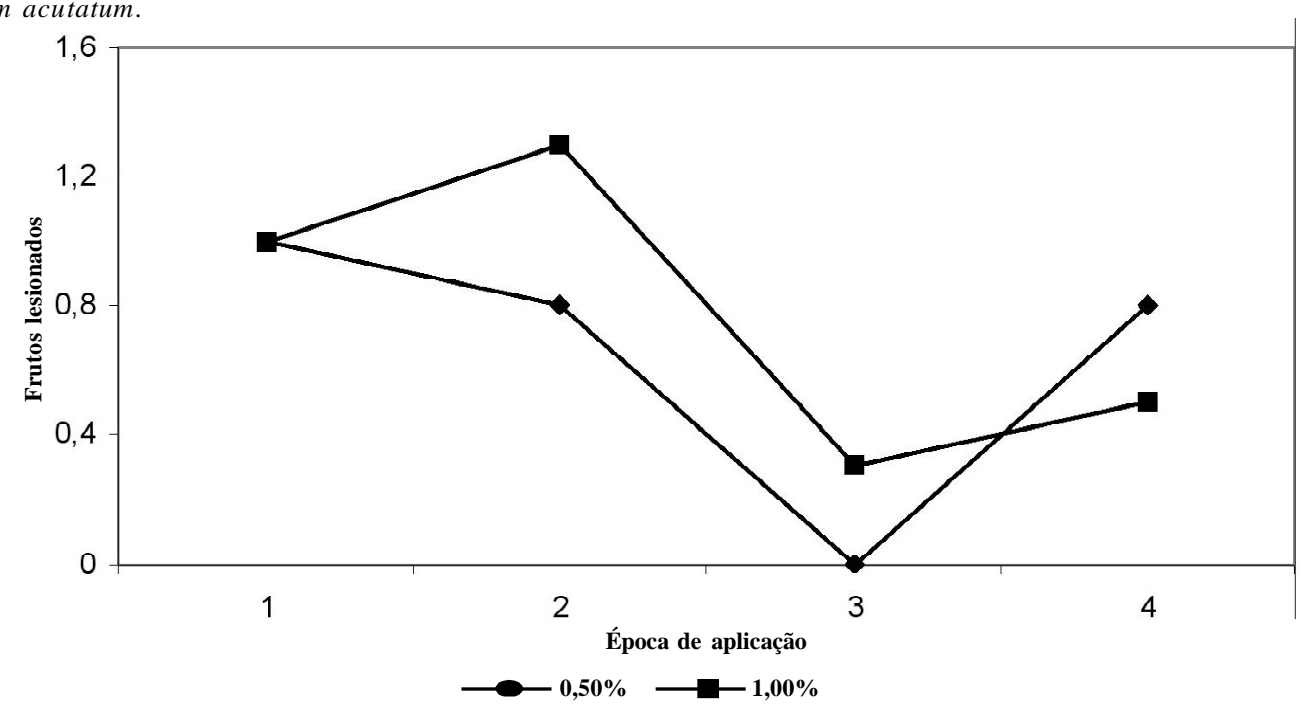

Épocas: 1: testemunha; 2: semanalmente; 3: quinzenalmente; 4: mensalmente.

O modo de ação do óleo de nim no controle de fitopatógenos vem sendo investigado por inúmeros pesquisadores. De acordo com Guleria \& Kumar (12), extratos de nim promoveram alterações e estimularam mecanismos naturais de defesa em Sesamum indicum L., contudo não inibiram significativamente os esporos de Alternaria sesami (Kaamura) Mohanty e Behera. Estes resultados estão de acordo com os obtidos anteriormente por Paul \& Sharma (19) no controle de Dreschlera graminea (Rabenh. ex. Schlech.) Shoemaker em cevada. Dentre os mecanismos ativados, constatou-se o aumento de peroxidases, compostos fenólicos e fenilalanina-amônia-liase $(12,19)$.

Segundo Amadioha \& Obi (2), a aplicação de extratos de óleo de nim em feijão caupi (Vigna unguiculata (L.) Walp) reduziu significativamente a ocorrência de lesões de antracnose provocadas por $C$. lindemuthianum, apresentando efeito fungitóxico superior ao fungicida benomyl. No controle de Pyricularia oryzae Cav. em arroz, o óleo e extratos de nim também promoveram reduções semelhantes ao fungicida carbendazin $0,1 \%$ i.a., comprovando o potencial para o controle da doença no campo (1). Resultados semelhantes foram obtidos por Paul \& Sharma (19), no controle de D. graminea em cevada e de Phytophthora infestans (Mont.) de Bary) em tomateiro (9).

Carneiro et al. (7) observaram que o óleo de nim foi eficiente no controle do oídio em feijoeiro, principalmente quando aplicado seis horas antes da inoculação, reduzindo em até $65 \%$ o número de lesões nas folhas. Contudo, os autores verificaram que o efeito protetor diminui com o passar do tempo, 54 e 78 horas. Segundo Martinez et al. (15) a exposição do óleo de nim a altas temperaturas e a radiação solar promove a degradação dos compostos ativos.

O potencial do nim em controlar doenças no campo, mesmo quando aplicado em baixas concentrações foi evidenciada em diversos trabalhos. Carneiro et al. (6) observaram que o óleo de nim foi eficiente em controlar oídio do tomateiro, quando aplicado nas concentrações de 0,25 ou $0,5 \%$. O controle da cercosporiose em amendoim foi obtido com o uso do óleo nas concentrações de 0,5 e 1,0\% (22). Em sementes de girassol a redução na incidência de Alternaria alternata (Fr.) Kiessler foi de quase $100 \%$, quando se utilizou extrato de sementes de nim a $1 \%(5)$.

Nas condições em que o experimento foi realizado observouse que apesar do óleo de E. citriodora ter inibido completamente o crescimento micelial de $C$. acutatum, nenhum efeito significativo foi observado no controle deste fungo no campo. O óleo de A. indica por sua vez foi eficiente em controlar o crescimento micelial e em reduzir a ocorrência de doenças quando aplicado nas flores, diminuindo tanto o abortamento floral, quanto o número de frutos sintomáticos originados de flores inoculadas.

\section{REFERÊNCIAS BIBLIOGRÁFICAS}

1. Amadioha, A.C. Controlling rice blast in vitro and in vivo with extracts of Azadirachta indica. Crop Protection, Leiden, v. 19, n. 5, p. 287-290, 2000 .

2. Amadioha, A.C.; Obi, V.I. Fungitoxic Activity of Extracts from 
Azadirachta indica and Xylopia aethiopica on Colletotrichum lindemuthianum in Cowpea. Journal Herbs, Spices \& Medicinal Plants, Amherst, vol. 6, p. 2, p. 33-40, 1998.

3. Bernardo, R.; Schwan-Estrada, K.R.F.; Stangarlin, J.R.; Cruz, M.E.S.; Pascholati, S.F. Fungitoxicidade de alguns óleos essenciais contra fungos fitopatogênicos. Fitopatologia Brasileira, Brasília, v. 23, p. 227, 1998.

4. Bonaldo, S.M.; Schwan-Estrada, K.R.F.; Stangarlin, J.R.; Tessmann, D.J.; Scapim, C.A. Fungitoxicidade, atividade elicitora de fitoalexinas e proteção de pepino contra Colletotrichum lagenarium, pelo extrato aquoso de Eucalyptus citriodora. Fitopatologia Brasileira, Brasília, v. 29, n. 2, p. 128-134, 2004.

5. Bhutta, A.R.; Rahber Bhatti, M.H.; Ahmad, I. Effect of seed diffusates on fungal population and germination of sunflower seeds. Helia, Novi Sad, v. 24 n. 34, p. 77-81, 2001.

6. Carneiro, S.M.T.P.G. Efeito de extratos de folhas e do óleo de nim sobre o oídio do tomateiro. Summa Phytopathologica, Botucatu, v. 29, n. 3, p. 262-265, 2003.

7. Carneiro, S.M.T.P.G.; Pignoni, E.; Vasconcellos, M.E.C.; Gomes, J.C. Eficácia de extratos de nim para o controle do oídio do feijoeiro. Summa Phytopathologica, Botucatu, v. 33, n. 1, p. 34-39, 2007.

8. Costa, A. F. Farmacognosia. Lisboa: Fundação Calouste Gulbenkian, 1986. 1032p.

9. Diniz, L.P.; Maffia, L.A.; Dhingra, O.D.; Casali, V.W.D.; Santos, R.H.S.; Muzubuti, E.S.G. Avaliação de produtos alternativos para controle da requeima do tomateiro. Fitopatologia Brasileira, Brasília, v.31 n.2, p. 171-179, 2006.

10. Fiori, A.C.G.; Schwan-Estrada, K.R.F.; Stangarlin, J.R.; Vida, J.B.; Scapim, C.A.; Cruz, M.E.S.; Pascholati, S.F. Antifungal activity of leaf extracts and essential oils of some medicinal plants against Didymella bryoniae. Journal of Phytopathology, Berlin, v. 148, p. 483-487, 2000.

11. Govindachari, T.R.; Sandhya, G.; Gopalakrishnan, G.; Banumathy, B.; Masilamani, S. Identification of antifungical compounds from de seed oil of Azadirachta indica. Phytoparasitica, Bet Dagan, v. 26, n. 2, p. 1-8, 1998.

12. Guleria, S.; Kumar, A. Azadirachta indica leaf extract induces resistence in sesame against Alternaria leaf spot disease. Journal of Cell and Molecular Biology, Orlando, v. 5, p. 81-86, 2006 .

13. Henz, G.P.; Boiteux, L.S.; Lopes, C.A. Outbreak of strawberry anthracnose caused by Colletotrichum acutatum in central Brazil. Plant Disease, St Paul, v. 76, p. 212, 1992.

14. Lee, S.O.; Choi, G.J.; Jang, K.S.; Lim, H.K.; Cho, K.Y.; Kim, J.C. Antifungal Activity of Five Plant Essential Oils as Fumigant Against Postharvest and Soilborne Plant Pathogenic Fungi. Plant Patholology Journal, Daejeon, v. 23, n. 2, p. 97-102, 2007.
15. Martinez, S.S. O Nim - Azadirachta indica: natureza, usos múltiplos, produção. Londrina: Instituto Agronômico do Paraná, 2002. $142 p$

16. Moreira, C.G.A.; Schwan-Estrada, K.R.F.; Bonaldo, S.M.; Stangarlin, J.R.; Cruz, M.E.S. Caracterização parcial de frações obtidas de extratos de Cymbopogon nardus com atividade elicitora de fitoalexinas em sorgo e soja e efeito sobre Colletotrichum lagenarium. Summa Phytopatologica, v. 34, n. 4, p. 332-337, 2008.

17. Motoyama, M.M.; Schwan-Estrada, K.R.F.; Stangarlin, J.R.; Fiori-Tutida, A.C.G.; Scapim, C.A. Indução de fitoalexinas em soja e em sorgo e efeito fungitóxico de extratos cítricos sobre Colletotrichum lagenarium e Fusarium semitectum. Acta Scientiarum. Agronomy, Maringá, v.25, n. 2, p. 491-496, 2003.

18. Ogbebor, N.O.; Adekunle, A.T.; Anobakhare, D.A. Inhibition of Colletotrichum gloeosporioides (Penz) Sacc. causal organism of rubber (Hevea brasiliensis Muell. Arg.) leaf spot using plant extracts. African Journal of Biotechnology, Nairobi, v. 6, n. 3, p. 213-218, 2007.

19. Paul, P.K.; Sharma, P.D. Azadirachta indica leaf extract induces resistance in barley against leaf stripe disease. Physiological and Molecular Plant Patholology, London, v. 61, n. 1, p. 313,2002

20. Pinto, C.M.F.; Maffia, L.A.; Casali, V.W.D.; Cardoso, A.A. In vitro effect of plant leaf extracts on mycelial growth and sclerotial germination of Sclerotium cepivorum. Journal of Phytopathology, Berlin, v. 146, n. 8/9, p. 421-425, 1998.

21. Ramezani, H. Fungicidal activity of volatile oil from Eucalyptus citriodora Hook. against Alternaria triticina. Communications in Agriculture and Applied Biological Sciences, Cambridge, v. 71, n.3, p. 909-914, 2006.

22. Srinivas, T.; Rao, M.S.; Reddy, P.S.; Reddy, P.N. Comparative effects of plant extracts and chemicals of the management of leaf spot of groundnut (Arachis hypogaea L.). Tropical Agriculture, London, v. 77, p. 58-60, 2000.

23. Stangarlin, J.R.; Schwan-Estrada, K.R.F.; Cruz, M.E.S.; Nozaki, M.H. Plantas medicinais e controle alternativo de fitopatógenos. Biotecnologia, Ciência e Desenvolvimento, Brasília, v. 11, p. 16-21, 1999.

24. Tanaka, M.A.S.; Passos, F.A.; Betti, J.A. Resistência de Colletotrichum fragariae e Colletotrichum acutatum a benomyl na cultura do morango no Estado de São Paulo. Scientia Agricola, Piracicaba, v. 54, n. 3, p. 139-146, 1997.

25. Tanaka, M.A.S.; Betti, J.A.; Kimati, H. Doenças do Morangueiro. In: Kimati, H.; Amorim, L.; Rezende, J.A.M.; Bergamin Filho, A.; Camargo, L.E.A. (Ed.). Manual de fitopatologia: doenças das plantas cultivadas. São Paulo: Agronômica Ceres, 2005. p. 489-499. 